\title{
One-incision approach (SILS) for retroperitoneal videoscopic adrenalectomy
}

\author{
Jacek Cywiński, Krzysztof Kuzdak, Krzysztof Kołomecki \\ Department of General and Endocrine Surgery, Medical University of Lodz, tódź, Poland
}

Videosurgery and other miniinvasive techniques 2010; 5 (2): 70-71

DOI: $10.5114 /$ wiitm.2010.14207

\begin{abstract}
Nowadays, nearly all adrenalectomies are performed with minimally invasive techniques to minimize surgery-associated trauma and improve the cosmetic effect. We have performed videoscopic retroperitoneal adrenalectomy via a single skin incision, using a single incision laparoscopic surgery port in a 56-year old woman with $4.5 \mathrm{~cm}$ incidentaloma of the left adrenal gland. Intra- and post-operative course was uneventful. Based on our experience and available literature, we believe that one-incision retroperitoneal adrenalectomy is a feasible option in selected cases.
\end{abstract}

Key words: adrenalectomy, one incision, single incision laparoscopic surgery.

\section{Introduction}

For a number of years contemporary surgery has focused on minimization of invasiveness of intervention. Procedures on adrenal glands are performed almost exclusively with video techniques via trans- or retroperitoneal access. These techniques result in noticeably better post-operative patient's condition, allowing mobilization of the patient on the day of surgery and shortening of the hospital stay. The cosmetic effect of these procedures is incomparably superior to so-called open surgery [1-3]. Three to five trocars are used for these procedures, and each one leaves a small scar. To minimize invasiveness and improve the cosmetic effect even more, a single port for laparoscopic surgery was proposed. The port has to be large enough to admit three different tools at the same time (single incision laparoscopic surgery - SILS). There are various names for this type of surgical access, specific for each manufacturer of the equipment. This technique is widely applied for laparoscopic cholecystectomy.

\section{Case report}

A 56-year old woman was admitted to our department for hormonally silent tumour of the left adrenal gland, $4.5 \mathrm{~cm}$ in diameter - so-called incidentaloma. She did not present with any signs or symptoms, nor did she have hypertension. The lesion was found on abdominal ultrasound performed for abdominal pain (uncomplicated cholelithiasis was also detected). Diagnosis was confirmed with computed tomography. Hormonal profile, including cortisol concentrations (in the morning and 24-h profile), adrenocorticotropic hormone (ACTH), aldosterone, renin, chromogranin $\mathrm{A}$ and electrolytes proved normal. The patient was referred for left adrenalectomy for incidentaloma.

The surgery was performed on 26 January 2010 with lateral retroperitoneal videoscopy through the SILS port. First, a 3-cm long skin incision was made to enter the retroperitoneal space and create some space with the surgeon's finger. Next, a silicon SILS (Covidien) port was placed. The space was inflated to $16 \mathrm{mmHg}$ 
and $30^{\circ}$ optics, a dissector and a $5 \mathrm{~mm}$ Atlas LigaSure electrotool were introduced via three working channels. After identification of the tumour it was dissected with the remnants of the adjacent suprarenal gland. Vessels surrounding the tumour were closed with LigaSure. The tumour was removed with the silica port. The tegument was sutured. Postoperative course was uneventful. The patient was discharged home on the $3^{\text {rd }}$ post-operative day.

The whole procedure lasted $90 \mathrm{~min}$ and blood loss was $50 \mathrm{ml}$.

\section{Discussion}

The urge to minimize perioperative trauma has led many centres to perform SILS procedures in patients with different diagnoses, including adrenal gland pathology.

In 2005 Hirano et al. presented 54 patients in whom adrenalectomy was performed via retroperitoneal access and a single, $4 \mathrm{~cm}$ long incision. A cylinder of the same diameter was positioned inside the incision. Adrenalectomy was performed without insufflation of $\mathrm{CO}_{2}$, and the instruments were placed through the cylinder. Regardless of the excellent results, the authors stressed that the technique is limited by the small operative area, which makes manipulation with the tools difficult [4]. Leong et al. from South Korea performed 9 laparoscopic adrenalectomies via a single incision. They believe that the method is safe, limits post-operative pain and gives an excellent cosmetic effect [5]. Walz et al. compared the results of retroperitoneoscopic adrenalectomy performed via a single, 2-cm wide incision (50 patients) and classical laparoscopic adrenalectomy with 3 ports (47 patients). The authors stated that patients operated on with single incision access suffered less post-operative pain, were discharged on average one day earlier and the rate of complications was similar in both groups. 'Classical' procedures lasted significantly shorter [6]. Castillo et al. from Chile proposed using 3-mm trocars and tools to minimize perioperative stress. With this method, they performed 112 adrenalectomies in patients with adrenal tumours smaller than $5 \mathrm{~cm}$ [7]. Marescaux et al. from Strasbourg published an interesting experimental study on left and right-sided adrenalectomy with the natural orifice transluminal endoscopic surgery (NOTES) technique through the vagina in an animal model and on cadavers [8].
Broader application of this technique is however limited by lack of specialized armamentarium for such procedures and it is now at the stage of early technical projects. It is possible that in a few years NOTES procedures will be performed quite universally, yet for now it remains the surgery of the future.

Comparing the results of other authors with our limited experience, it should be concluded that single incision procedures ought to be reserved for selected, relatively uncomplicated cases. Operating with parallel tools is quite difficult. When facing intraoperative technical problems, for instance haemorrhage, finding a solution may not be easy. We believe that the length of post-operative hospital stay depends on so many factors that the mean difference of one day cannot be attributed solely to surgical technique. We believe that better cosmetic effects, as put forth by other authors, is disputable. In surgery of the gall bladder, where the incision is made within the umbilicus, this effect is indubitable. However, the advantage of trading three $0.5-1 \mathrm{~cm}$ long scars for one $2-3 \mathrm{~cm}$ long scar in the lumbar region is not so obvious, while retrieval of the tumour through a larger incision is definitely easier.

To sum up, we believe that retroperitoneal adrenalectomy can be successfully performed in selected patients.

\section{References}

1. Wang DS, Terashi T. Laparoscopic adrenalectomy. Urol Clin North Am 2008; 35: 351-63.

2. Otto M, Dzwonkowski J, Grzela T, et al. Adrenalektomia laparoskopowa u chorych w podeszłym wieku. Wideochirurgia i inne techniki małoinwazyjne 2006; 2: 65-9.

3. Kołomecki K, Hedayati M, Cywiński J, et al. Wideoskopowe operacje nadnerczy z dostępu pozaotrzewnowego. Pol Przeg Chir 2008; 80: 662-72.

4. Hirano D, Minei S, Yamaguchi K, et al. Retroperitoneoscopic adrenalectomy for arenal tumors vis a single large port. J Endourol 2005; 19: 788-92.

5. Leong BC, Park YH, Han DH, et al. Laparoendoscopic single-site and conventional laparoscopic adrenalectomy: a matched casecontrol study. J Endourol 2009; 23: 1957-60.

6. Walz MK, Groeben H, Alesina PF. Single-access retroperitoneoscopic adrenalectomy (SARA) versus conventional retroperitoneoscopic adrenalectomy (CORA): a case - control study. World J Surg 2010; 34: 1386-90.

7. Castillo O, Sanchez-Salas R. Which patients are suitable candidates for laparoscopic adrenalectomy with needlescopic instruments? Nat Clin Pract Urol 2009; 6: 10-1.

8. Peretta S, Allemann P, Asakuma M, et al. Adrenalectomy Rusing natura orfice transluminal endoscopic surgery (NOTES): a transvaginal retroperitoneal approach. Surg Endosc 2009; 23: 1390-6. 